\title{
Mediastinal Neuro-Fibro-Lipoma with Atypia: A Case Report
}

\author{
Kishor Taori, Suresh Dhakate, Jawhar Rathod, Amit Disawal, Anand Hatgoankar, \\ Rohit Khisti, Mansi Jain, Shashikant Mane, Rahul Jain \\ Department of Radiodiagnosis, Government Medical College, Nagpur, India \\ Email: kishortaori@gmail.com
}

Received 7 January 2014; revised 7 February 2014; accepted 14 February 2014

Copyright (C) 2014 by authors and Scientific Research Publishing Inc.

This work is licensed under the Creative Commons Attribution International License (CC BY). http://creativecommons.org/licenses/by/4.0/

(c) (i) Open Access

\begin{abstract}
Mediastinal lipomatous tumors with additional malignant soft tissue components are exceedingly rare. Patients can have substantially large sized tumors with long duration of symptoms and can be misinterpreted on radiographs. Enhancing soft tissue component within a fat density lesion within the mediastinum is alarming and should raise the suspicion of sarcomatous component. Along with diagnostic imaging, selective CT guided biopsy/FNAC from the enhancing soft tissue component can help in making correct diagnosis.
\end{abstract}

Keywords

Mediastinal; Neuro-Fibro-Lipoma; CT Scan

\section{Introduction}

Mediastinal malignant lipomatous tumors (including primary mediastinal liposaromas and those of the pericardium) are very rare which occur in adults around 5th to 6th decade [1]-[3]. They are usually liposaromas. Four main types have been described: myxoid, well differentiated, dedifferentiated and pleomorphic [4]. "Mediastinal lipomatous tumors with neural \& fibrous components in additional to atypical cells" have not been reported yet. Radiographs are often not very conclusive. Contrast enhanced CT scan is the imaging investigation of choice. Surgical excision is treatment of choice [4] and close follow up is strongly recommended [5].

\section{Case Report}

A 30-year-old female presented with complaints of breathlessness \& cough since 1 month. There was no history of similar complaints in past, hemoptysis, previous chest infection or any surgery. On examination patient had tachypnoea \& bilaterally reduced breath sounds. 
Patient was first evaluated with a chest radiograph PA-view (Figure 1) which revealed diffuse homogenous ill-defined soft tissue radio-opacity involving both the lung fields predominantly in middle \& lower zones silhouetting both the cardiac borders and obscuring both cardiophrenic and costophrenic angles.

Subsequently CT scan was done before \& after IV contrast administration.

CT scan revealed (Figures 2-4) a large heterogeneous predominantly anterior mediastinal mass with large fat component and ill-defined enhancing soft tissue component within, encasing the heart $\&$ great vessels with associated collapse of right lower lobe, anterior, medial \& lateral basal segments of left lower lobe $\&$ both middle lobes. There were no calcifications and no evidence of any bone destruction/erosion. Both adrenal glands were found to be normal.

Final diagnosis was made by selective CT guided biopsy, which was done from the soft tissue component of lesion using $18 \mathrm{G}$ needle with two passes after local infiltration of anesthetic agent (lignocaine). Patient did not have any post-biopsy complication.

Biopsied material was sent for histopathological examination (Figures 5 and 6) which revealed groups of mature lipocytes along with occasional cells showing mild atypia. Also seen were bundles of spindle cells with moderate cytoplasm. Histopathological diagnosis was neuro-fibro-lipoma with atypia.

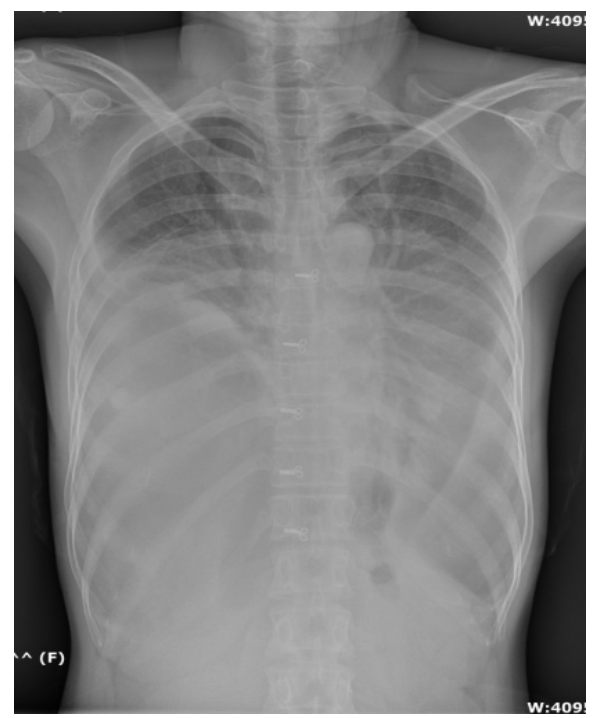

Figure 1. Chest radiograph PA-view showing diffuse homogenous ill-defined soft tissue radio-opacity involving both the lung fields predominantly in middle \& lower zones silhouetting both the cardiac borders and obscuring both cardiophrenic and costophrenic angles.

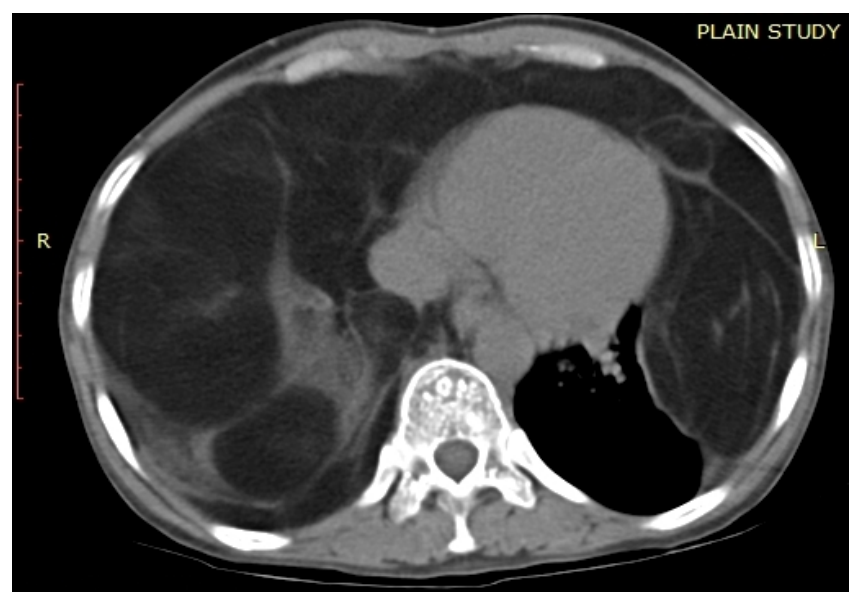

Figure 2. Axial CT plain study showing large lesion predominantly containing fat with soft tissue component encasing the heart. 


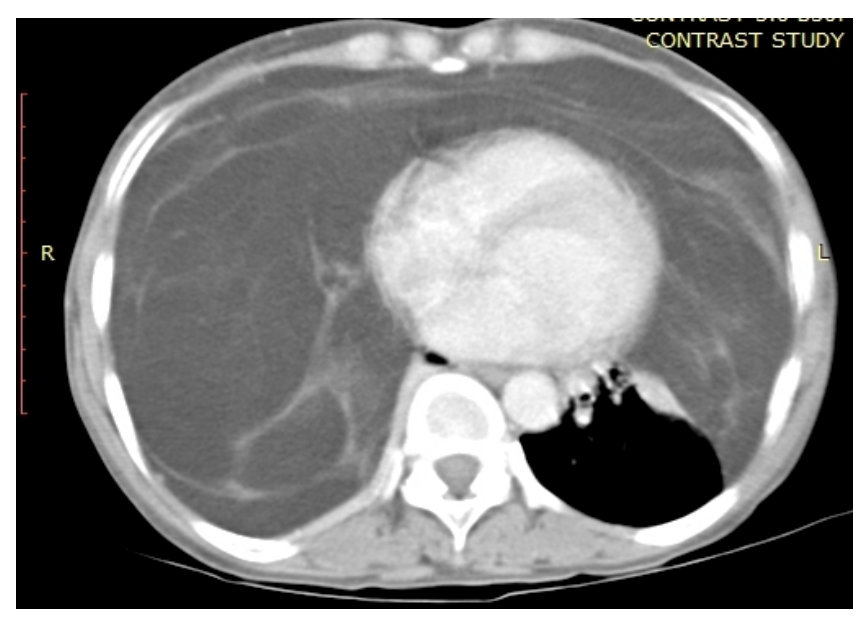

Figure 3. Axial CT contrast study showing large lipomatous lesion with enhancing soft tissue component occupying most of the thoracic cavity.

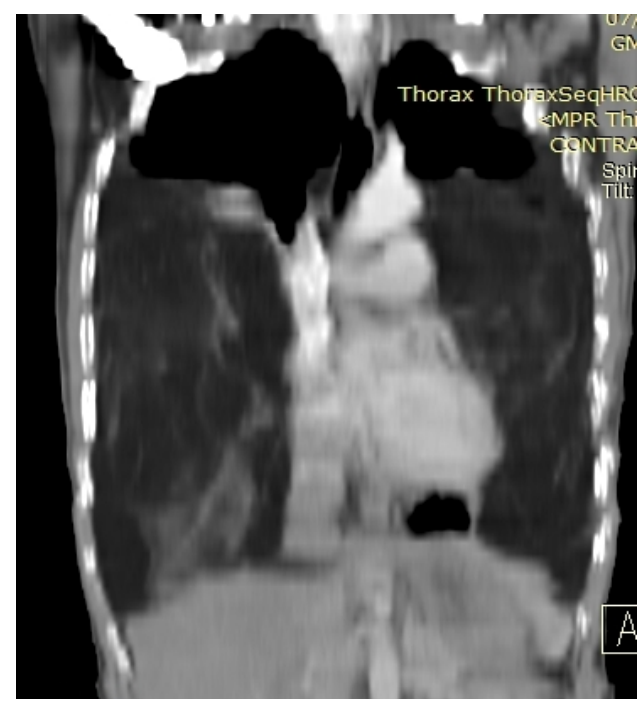

Figure 4. Contrast CT-coronal reconstruction showing predominantly fat containing lesion with enhancing soft tissue component involving the most of thoracic cavity encasing heart \& great vessels.

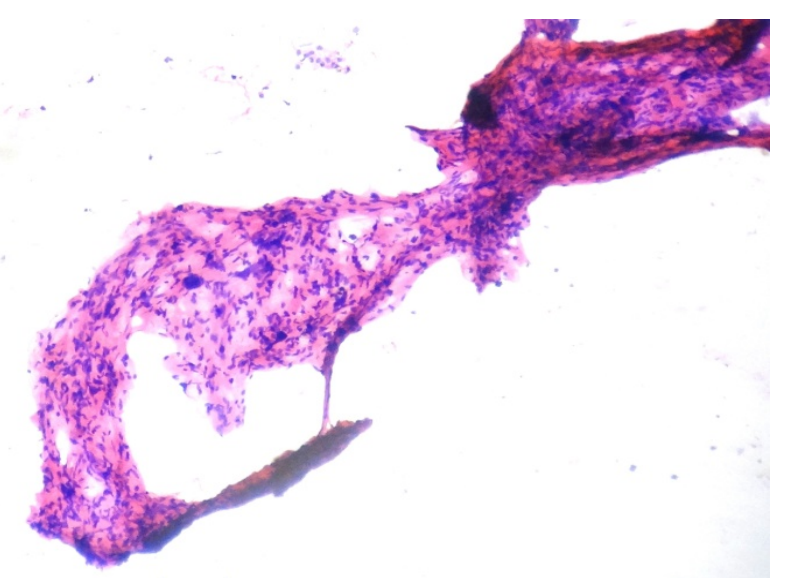

Figure 5. Histopathology reveals groups of mature lipocytes along with occasional cells showing mild atypia. Also seen were bundles of spindle cells with wavy nuclei with moderate cytoplasm. 


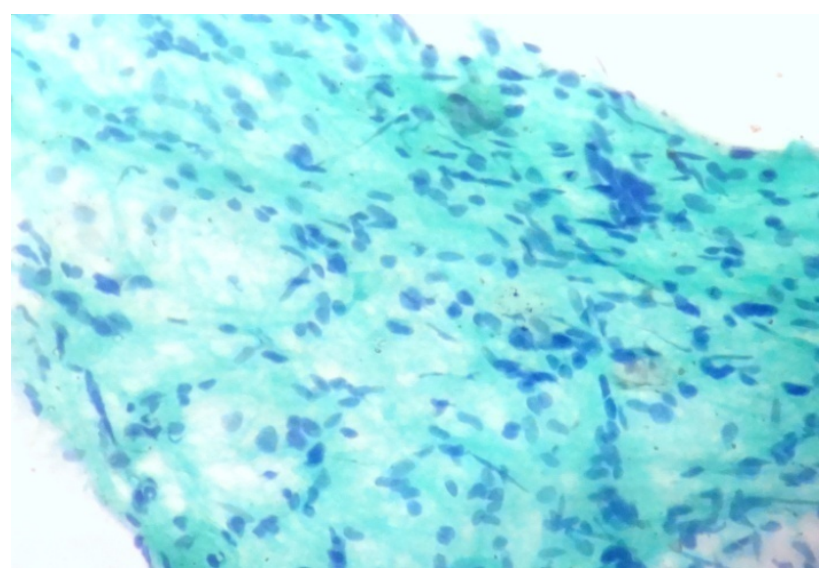

Figure 6. Histopathology reveals groups of mature lipocytes along with occasional cells showing mild atypia. Also seen were bundles of spindle cells with moderate cytoplasm.

\section{Discussion}

Mediastinal malignant lipomatous tumors are very rare [1], [3]. They occur in adults around 5th to 6th decades. They are usually liposarcomas. Four main types have been described: myxoid, well differentiated, dedifferentiated and pleomorphic [4]. Mediastinal lipomatous tumors with neural \& fibrous components in addition to atypical cells have not been reported previously, the significance of which seems obscure at present.

Patients usually present with chest pain, breathlessness \& cough. Radiographs are often not very conclusive. Contrast enhanced CT scan is the imaging investigation of choice which reveals low attenuating masses with HU values from -50 to -150 [1]. Soft tissue component may be present with variable attenuation which shows enhancement following IV contrast. Presence of soft tissue component (shows higher attenuation) points to sarcomatous/malignant component. Calcifications are usually not present. Any erosion of bone destruction is uncommon. Histopathological diagnosis can be made by performing selective biopsy from the soft tissue component of the lesion under CT guidance.

Surgical resection can be attempted and excision is the treatment of choice in resectable cases [4]; however encasement of great vessels, adherence to chest wall can preclude it. Radiotherapy \& chemotherapy can be adjunctive to which such tumors are poorly responsive but can be the only treatment option in inoperable cases.

\section{References}

[1] Barbetakis, N., Samanidis, G., Samanidou, E., Kirodimos, E., Kiziridou, A., Bischiniotis, T., et al. (2007) Primary Mediastinal Liposarcoma: A Case Report. Journal of Medical Case Reports, 1, 161. http://dx.doi.org/10.1186/1752-1947-1-161

[2] Saeed, M., Plett, S., Kim, G.E., Daldrup-Link, H. and Courtier, J. (2010) Radiological-Pathological Correlation of Pleomorphic Liposarcoma of the Anterior Mediastinum in a 17-Year-Old Girl. Pediatric Radiology, 40, S68-S70. http://dx.doi.org/10.1007/s00247-010-1797-1

[3] Kindl, T.F., Hassan, A.M., Booth Jr., R.L., Durham, S.J. and Papadimos, T.J. (2006) A Primary High-Grade Pleomorphic Pericardial Liposarcoma Presenting as Syncope and Angina. Anesthesia \& Analgesia, 102, 1363-1364. http://dx.doi.org/10.1213/01.ane.0000205753.59524.21

[4] Plukker, J.T.M., Joosten, H.J.M., Rensing, J.B.M. and Van Haelst, U.J.G.M. (1988) Primary Liposarcoma of the Mediastinum in a Child. Journal of Surgical Oncology, 37, 257-263. http://dx.doi.org/10.1002/jso.2930370410

[5] Wang, J.G., Wei, Z.M., Liu, H. and Li, Y.J. (2010) Primary Pleomorphic Liposarcoma of Pericardium. Interactive CardioVascular and Thoracic Surgery, 11, 325-327. http://dx.doi.org/10.1510/icvts.2010.239723 